\title{
Widening access and literacy
}

\section{Joseph Lo Bianco}

\section{Introduction}

Identifying literacy as a factor impacting on higher education access compels researchers and policy makers to address questions of post-access performance, such as retention, completion or graduation rates, as well as entry. Moreover, bringing literacy into the paradigm of widening access research will require attention to the multiple ways that literacy itself is understood and represented. These can range from the straightforward characterisations of what literacy is, how it is learned and used, that are classically found in most policy texts, to the more complex, socially situated and variable notions of literacy favoured by in any academic researchers and literacy educators. These disparities suggest that access research needs to extend the range of its interests to include the quality of educational experience within higher education, and specifically teaching and learning in academic settings.

\section{Literacy and literacies}

Three interlocking notions of literacy are used in the present chapter. First, literacy is seen as the sets of 'codes, modes and meanings' (Lo Bianco and Freebody 2001: 14) associated with reading and writing. Second, researchers' accounts of literacy as variable and socially located are regarded as persuasive in explaining the real world presence of literacy since these shed light on how individuals and various social groups relate to institutions in which communication activity, especially literacy, constitutes the dominant practice (Heath 1983; Baynham 1995; Street 1995; Prinsloo and Breier 1996; Barton and Hamilton 1998; Barton et al. 2000; Hornberger 2002). Third, though not extensively discussed here, is the sense that literacy should also be understood as cultural practice (Collins 1995; Kalman 1999), relevant in discussing cultural barriers to access.

Specific to education is Freebody and Luke's (1990) characterisation of four 'resources' that sustain effective personal literacy. These resources are an ability to break the code of texts; an ability to participate in the meanings of texts; an ability to use texts functionally; and an ability to analyse texts critically, by asking questions about the ideologies they carry. Together these resources form a general capability that literacy educators ought to aim for, far richer and more appropriate to contemporary circumstances than commonly heard appeals for a return to basics. Foregrounding critical and creative dimensions in definitions of literacy also suggests that all teaching and learning endeavours, and research on widening access to higher education, should address the specific literacy demands of subject and discipline specialisations and, possibly explicitly, conceive of all teaching as involving an extension of learners' literacy.

\section{Literacy and policy}

Examples of literacy policy in the 1990s suggest some of the conditions under which policy makers are prepared to devote attention to adult literacy education. In Australia (Wickert 2001; Falk 2001), the UK (Baynham 2003), and the US (Collins 1999; Street 2003), public policy attention has been accompanied by the imposition of bureaucratic surveillance and even control. This has involved rigid 
normalisation of assessment, strict centralised programme accountability, explicit criteria prioritising labour market rationales and goals over community rationales, or vernacular contexts and settings, and, often, the privileging of empirical positivistic data gathering methods over qualitative ethnographic analysis (Street 2003). Surrender of professional pedagogical autonomy is the payment demanded of literacy teachers, researchers and advocates in exchange for the allocation of public resources.

Despite their richly descriptive and powerfully explanatory findings the qualitative nature and ethnographic approaches typical of New Literacy Studies (Street 2001, 2003; Baynham 2003) have little traction in much contemporary public policy. Dominant instead are international comparative statistical collections, exemplified by the International Adult Literacy Survey of 1996, undertaken by the OECD in collaboration with Statistics Canada, and involving the participation of 20 countries (Australian Bureau of Statistics 1996; OECD 1997; Hagston 2002). Epitomising the privileging of research modes are the provisions of the No Child Left Behind Act of 2001 in the United States, which ranks acceptable research according to 'scientific' rankings that narrowly conceive acceptable practice in quantitative terms, and judge these to be the sole or dominant basis for policy formulation. This practice is labelled 'evidence-based' policy making. It is unlikely that some potentially negative effects of literacy on access to higher education will be researched by approaches that concentrate exclusively on randomised experimental, and replicable, large-scale quantitative methodologies. This will mean that overt impacts (e.g. competence barriers to access of academically powerful registers of knowledge required by the prescribed genres of various disciplines in higher education), and subtle impacts (e.g. the dissuading effects on motivation to pursue higher education induced by a culture of privileged academic literacy, functioning as elite ideology and exclusive identity), will remain outside policy influence.

Widening access requires engagement with perspectives such as those brought together in New Literacy Studies, in which out-of-school, or university, literacy events and practices are connected with the uses and values of literacy within educational institutions. Widening access also requires engagement with the pedagogical promise of perspectives from the international Multiliteracies movement (Cope and Kalantzis 2000), combining communication modality with teaching. Higher educational institutions are quintessentially literate institutions, in which most institutional events are literacy-specific, literacy-intense and defined by, and made through, literate exchange. Historically cultural barriers militating against access and participation in higher education have been erected on the basis of literacy culture; denial and negation of the range, complexity and subtlety of the literate repertoire to socially determined categories. The refinement, cultivation and display of elevated literate practice constituted, and largely still constitute, the defining character of membership of higher education and in particular the discourse communities around which its members gravitate and identify.

Many critics of the exclusionary culture of higher learning identify its norms and practices as socially and culturally repressive. Access to these practices cannot be limited simply to unqualified participation, but to diversifying the language and cultural expressive modes in which it operates. These claims are not merely for reducing barriers between abstract conceptions of the institution and class or culturally diverse populations, but between formal and institutionalised practices of education and 'ordinary life' (Hamilton 2001).

\section{Literacy in labour market and human capital planning}

In its advocacy of 'life-long learning', the OECD (1996) estimates that only one-third of all adults in the majority of 'OECD countries' have achieved 'minimum' rates of literacy and numeracy. They connect this generalisation with trends about social activity, and economic production, towards greater knowledge intensiveness, and towards deepening general links between economies and education, 
and more widely diffused information and communications technologies. From these connections emerge notions of the 'learning society' (OECD 1996: 37), a basic tenet of lifelong learning.

Although falling short of characterising literacy as a socially situated practice with personal and cultural meanings, the OECD nevertheless stretches the classical restricted notion of literacy as simply a psychological and motor skill, as follows: 'The very notion of literacy has evolved; in addition to reading, writing and numeracy skills, people also require technological and computer literacy, environmental literacy and social competence' (OECD 1996: 39). For the OECD signs of articulation among or blurring of distinctions between, formal education and training, and learning in non-formal settings, and the related contraction of age boundaries between secondary and higher education, motivate what is ultimately a strong tie between 'culture' and literacy, viz., 'Raising a country's literacy profile requires a change in its culture' (OECD 1997: 85).

It is often stated within policy contexts that investing in literacy education offers a large number of 'quiet' contributions to the economy. The claimed quiet contributions are many and powerful: that workers become more productive, that private income levels increase, that government revenues rise, that individuals attain a better quality of life, that poverty is reduced, that unemployment decreases, that crime rates decline, that public assistance is reduced, that indicators of good health increase and that child-rearing practices improve. As if this roll-call were not impressive enough, other 'quiet' contributions include increased participation rates in community activities and the bolstering of various measures of citizenship.

Repeatedly the conviction that literacy is an unproblematic contributor to boosting economic competitiveness is expressed. While literacy researchers are committed to explicit language and literacy provision for adults, there is scepticism (Graff 2001; Olson and Torrance 2001) about the unproblematic, confident, basis of such claims. According to Baynham (2003) only bilingual education seems to excite as much controversy as adult literacy, citing in particular the repeated claim of governments that standards of literacy have declined, and that such declines threaten the competitiveness of national economies, with the optional, but frequently encountered rider, that these declines are attributable to 'modern' or 'experimental' or 'faddish/trendy' teaching methodologies.

Adult literacy policy investigations are replete with heady tones of newly discovered public neglect and curative policy evangelism, in extremis primary schools will be punished for laxity, teachers for incompetence, and adults saved from lives of imminent criminality, destitution or marginalisation. A cursory examination of what policy inquiries actually produce, however, reveals only regimes for testing literacy standards, usually in rigidly and narrowly normalising ways, accompanied by public declarations demanding improvement. Inquiries are often entrusted to well-meaning public notables whose pronouncements, sometimes featuring shocked earnestness, contribute to what Graff (2001: 2) calls the 'tireless but tiresome' constitution of literacy in crisis. As a historian of literacy Graff also notes in the elevated significance attributed to literacy, and its standards, continual crises: '... I cannot recall a time when literacy was not in a crisis' (p. 3 ); finding that in public panics about educational crisis literacy standards are 'symptoms and symbols, causes and consequences' ( $p .3)$; and he cites Searle that higher education is 'essentially and continuously contested territory' (p. 4).

\section{Reform}

Western education and training systems have been subjected to almost relentless reform over recent decades. This has been due to policy settings that associate educational activity closely with labour market and wider economic phenomena. The inconclusive results of these policies have produced much chopping and changing in policy moves. Degree level higher education is one of the sites in which educational planners have aimed to negotiate policy settings to give governments greater leverage. This has meant increased numbers of participating mature age and part-time candidates in 
higher education. Driving these changes have been conceptualisations of access to higher education that are structural and financial in origin, locating policy initiatives to enhance participation and success rates in higher education within the financial means available to hesitant participants, or within needed reforms to the structural operations of institutions. These changes accommodate lifecircumstances, competing occupational demands and financial restraints on candidates. The present chapter argues that alongside these necessary concerns we need to add attention to cultural, and specifically literacy, reforms; literacy itself understood both structurally (that is, the quantum and nature of literate capability that learners require to access higher education and succeed there) and as culture (that is, literate practice as indexical of values and producer of social identities, particularly those that higher education presumes, creates and communicates).

Structural articulations among education providers have modified the traditional pathways from secondary schooling to higher education via post-compulsory level examinations, supplementing these with age and alternative-mode entry arrangements and schemes. These more flexible routes are an expression of public sector calculations that access to higher education is an investment in wider economic competitiveness at a time of rapid transfer of economic attention from protective measures for national economies to 'defensive' investments in education and training, though it must be noted that despite this sense of the economic power of higher education English-speaking countries have not been prone to 'invest' in general education. These changes have in turn coincided with a greater commodification of higher education, introducing much greater numbers of international students, in the main of non-English-speaking background, into English medium education.

Flexibility in access pathways has extended to award and certification structures, including crossinstitutional credit transfers, to encouragement of corporate sector investment in courses, designated research priority, including patent and copyright control arrangements that modify traditional academic patterns. Open access provision, including online and flexible delivery modalities, have further enriched these institution-based provisions. In this context the notion of lifelong learning has been elevated to prominence, partly under the auspices and leadership of the Organisation for Economic Cooperation and Development. It has also been under the influence of the OECD that literacy, adult literacy specifically, and elaborated kinds of non-prose literacy (e.g. 'information' or 'document' literacy, 'quantitative' literacy, or numeracy) have been given attention in policy discussions in developed societies. Many of these societies had until relatively recently regarded literacy as a phenomenon that had been 'dealt with' in earlier eras of social development, relevant now only to primary schooling, and having few public policy implications beyond the occasional remedial programme for newly arrived immigrants or for some disadvantaged mainstream sections of the population. The 1996 International Adult Literacy Survey marked the presence of the OECD within this field of education policy making, made statistical data collection the principal means for this work, and connected literacy education closely to economic competitiveness of nations and to 'social cohesion' (OECD 1997). The data from the IALS measures literacy on three axes of performance prose, document and quantitative literacy - along five levels.

One manifestation of the above changes in access to higher degree studies has been the rise in academic support centres, sometimes called study support centres or student learning support units, in higher education institutions. These aim to support what is increasingly called the 'tertiary literacy' development of new cohorts of students, often not studying in their native language, but are also a reflection that what counts as literate capability has itself changed and can no longer be reliably predicted as a linear extension to school, gained literacy. This, in turn, reflects a much wider understanding of literacy as a contingent practice, in which literacy is seen less as an autonomously and endlessly transferable skill but rather as a variable set of practices influenced by setting and purpose. This shift of attention and understanding in the nature of literacy, its ethnographic and 'ideological' characteristics (Street 1995, 2001), was decisive in explaining why literacy programmes designed in developed countries and transposed to aid contexts sometimes failed to achieve the 
anticipated results by focusing on the local meaning and relevance of literacy. As part of this new regard for a more complex literacy, a notion of literacy sensitive to its differences, is the emergent sense that academic disciplines operate with distinctive literacies, evident in the particular literacy demands their prescribed texts require and how the displaying and demonstration of learning are assessed in that discipline. In some higher degree settings there is growing awareness that knowledge of such disciplinary literacies cannot always be taken for granted and that academic teaching includes induction into such literacies.

In recent decades there has been growing government concern about the changing structure of employment and the perceived need for new training strategies to promote global competitiveness. The decline of manufacturing and the rapid shift of economic power towards post-industrial services and information, based operations combine with sometimes radical changes in workplace relations and operations, and a number of other reinforcing factors, such as the decline in job access and preparation modes, such as the traditional apprenticeship system. The dominant way that new employment is characterised emphasises worker flexibility, adaptability and mobility, in work settings with flatter job hierarchies, comprising fewer sharply demarcated occupational categories and generally less rigid and vertical structures of operation. Labour is now expected to be more mobile in response to market driven shifts in location or occupational content. These changes tend to reinforce communication, and communication effectiveness, as factors in labour market selection, success and operations.

These kinds of communication issues, reinforced by immigration patterns which have made workforces multilingual and multi-literate, are represented in vocational education and training policies, including basic skills for employment, as key questions on the agenda of public policy making. Key target groups in these policy aspirations have been school leavers, especially 16 to 19year-olds, the long-term unemployed, targeted minorities, and designated disadvantaged regional areas, typically zones undergoing de-industrialisation. As a result, in Australia, the UK and the US new organisational formations which link industry with education and training providers have emerged. Examples have been the Training and Enterprise Councils in the UK, the Private Industry Councils in the US and the Industry Training Advisory Bodies in Australia.

One function of such cross-sectoral organisational arrangements has been to establish local initiatives in training associated with local industrial (or post-industrial) employment generating and sustaining intervention policies. Some such bodies conduct skills training; others coordinate it, and attract or generate investments on the basis of various kinds of schemes. The ITABs in Australia are directly responsible for devising Industry Training Packages comprising complex curricula, assessment and qualifications frameworks, attempting to specify stocks of knowledge, skills, contexts and settings for application. These partnerships forged across government, business and employee organisations with education and training providers also aim to establish occupationally relevant standards of training, accreditation and recognition. Australia has been moving towards a unified national vocational qualifications framework, comprising targets, modes of quality assurance and mechanisms for determining equivalence across jurisdictions and systems. When it is separately identified, literacy is seen as either an add-on training component in these schemes, or an integral, infused aspect of all teaching content. One implication of these initiatives in the provision of post-school training in institutionalised vocational and training systems, or adult basic education schemes and initiatives, is a notion of 'widening access' where literacy is critically important in all professional and vocational disciplines.

\section{Literacy mediates cultural and academic barriers}

The present authorisation of the United States Higher Education Act of 1965 expires in September 2004. A recent report (Wolanin 2003) aiming to extend authorisation for a further four years was 
conducted by the Washington DC based Institute of Higher Education Policy (IHEP) (online at www.ihep.org). The IHEP report refers to US Census data showing that disparities between college participation rates of high and low-income groups, and between selected minority groups and Whites, have been remarkably persistent for the past 30 years. Family income remains a major predictor of college access today, having narrowed only about 10 per cent since the 1970s, while some comparisons, Whites-Blacks and Whites-Hispanics, have actually widened. These disparities persist within an overall pattern of increase in participation rates for all groups, and projected significant further rises over the next 15-20 years.

The approach advocated in Wolanin's study is to discuss widening access within a wide remit addressing higher education persistence, or post-access performance, especially for first-generation admissions to higher education, that is those whose parents had not attended higher education. This policy challenge goes considerably beyond removing institutional and structural barriers, or financial and academic barriers, to participation. Social and cultural barriers, exemplified in identity remarks such as 'People like us don't go to College' (p. 9), require that access research extend beyond entry facilitation by means of structural or financial policy to encompass research and policy-oriented data sensitive to the cultural consequences and challenges of intergenerational changes in family education patterns.

Similarly, addressing 'cultural competence' and 'English language acquisition history' is recent Australian research by Borland and Pearce (2002). This work identifies student language and cultural background factors that institutions can address to understand their readiness to study. Also discussed are the processes of pre-enrolment information gathering that institutions undertake to provide improved learning experiences for students from diverse language, cultural and social backgrounds, mainly by offering 'targeted academic support in language and learning' (p. 123). Both of these studies point to various kinds of 'academic adjustment' challenges that students from underrepresented backgrounds may encounter, and suggest that such cultural and social barriers be embraced within a thorough and comprehensive widening access commitment.

Social and cultural barriers are many and variable, linking to parental education attainment, migration history, family income, race, ethnicity and various social identities, and the compounding effects of aggregations of these factors. Social and cultural barriers to access are also, often and deeply, manifested and mediated by academic English proficiency, and especially literate English capability, which in turn forms links to various academic barriers.

This wide array of background variables supports Absalom and Golebiowski's (2002) argument that the 'massification' of higher education has produced major changes in teaching and learning in higher education, shaped by extra-institutional forces of multiculturalism, economic rationalism and computerisation. These forces have elevated the importance of tertiary literacy as a field of research and as a practice important in assisting undergraduate and even graduate students, and in response call for ongoing professional dialogue between tertiary literacy specialists and academics from other fields of study. This idea is considered from a reinforcing but different angle by Bock and Gough (2002) who, specifically discussing groups previously excluded from South African higher education, call for teaching and assessment practices in undergraduate courses to explore the inclusion of tasks in the narrative and creative modalities of expression. They point to powerful traditions of both primary and secondary oral discourse types among traditional Xhosa, including rhetoric and genres of narrative oral literature, and suggest strong implications for teaching and assessment if policies of widening access are to be crowned with success.

According to Bock and Gough, teaching in higher education needs to accommodate wider learner characteristics, and explore conventional modes for how knowledge mastery is displayed and assessed, drawing on genres of a narrative and creative character in addition to the more 
academically conventional ones. In any case distinctive disciplinary literacies are a longstanding feature of conventional academic work, as Kirkpatrick and Mulligan (2002) show by reference to the amounts and kinds of reading required between social science and engineering academic programmes. The volume and character of reading is radically different, requiring a critical, personally engaged, occasionally sceptical, opinion forming disposition in the former and an information absorbing and accumulating tradition in the latter.

Cultural barriers and their connection with literacy are often well perceived by policy makers who might, however, name the policy goal in different ways. Widening access research needs to be sensitive to the different ways in which the task is named and constituted in different settings. For example, South African policy on the education of adults in the post-apartheid period has specifically targeted low-literacy adults. Some researchers note a 'disturbing' gap between what policy makers determine as a 'problem', and the likely effectiveness of the proposed solution. Literacy is particularly prone to this kind of gap. Policy attention comes at a price, sometimes in the form of 'illiteracy eradication campaigns' of the kind that literacy ethnographers consider unlikely to succeed, stigmatising of learners and simplistic. The claims, perhaps the aspirations, of policy makers for payoff from investment of public resources in literacy campaigns are high levels of politicisation and contestation around the claims for and results from such investments. Many researchers interested in literacy education lament the deleterious effects of literacy policy, to the extent that the interest of public policy makers seems to always be accompanied by restrictions to the kinds of research that are supported and to the professional latitude that literacy professionals are conceded.

Working with such dilemmas in South Africa's complex multilingual reality, and its history of extreme educational exclusion, Janks (2000) has devised an analytical framework for connecting critical social analysis with four dimensions of needed education and language action, Access, Diversity, Domination and Design. This framework is characterised by an education policy aiming to overcome past language oppression. While forthrightly naming and dealing with the history of language domination Janks' approach still acknowledges the universal esteem and demand for English literacy, realised through the notion of access. However, English medium higher education access is pedagogically difficult to implement, and ultimately problematical, if it is predicated upon cultural assimilation. and therefore in Janks, pedagogical framework principles of diversity accompany access. Design is a principle that acknowledges that codes, and modes, of literacy, though often employing literacy elements (such as text genres, or academic rhetorical modes, and computer multimodality) that are 'extra-local', are not imposed and therefore culturally alienating but negotiated and re-made according to local meanings, and the socially situated literacy practices of students.

\section{Higher education language and literacy policies}

An immediate consequence of an awareness of the deeper cultural meanings for widening access is to see higher education institutions as quintessentially literacy-dependent entities, where by far the single greatest conventionalised activity is literate practice. In effect, higher education institutions are aggregations of interrelated intellectual communities whose primary practice and principal instrument is literate behaviour. The varying literate practices of the diverse disciplinary fields that comprise higher education institutions mediate admission or exclusion, determine knowledge acquisition, govern performance and signify identity and professional culture.

The implications of this centrality of literacy to admission, success, and membership of higher education, within a policy project of widening access, require measures to facilitate the admission of greater numbers to the literacy-dependent scholarly life of the institution, but also to attend to the progressively more complex literate demands of teaching and learning. Institution-wide and institutionspecific language policies are required. These should be formulated around the language conventions 
of general academic performance, subject specific genres and discourses, and how learning is demonstrated, assessed and displayed. The globalisation of higher education, combined with the growing treatment of higher education certification as a traded commodity, require that the increasingly diverse language characteristics, problems and needs of learners, more and more often not first language users of English, sometimes from second dialect backgrounds, should be given prominence in such policies.

Higher education institutions need to regard language and literacy as a resource, a social and intellectual resource, whose explicit management and cultivation they undertake as part of their mainstream operations. The development of literacy policies should be the principal means for cultivating and extending literacy resources. These policies would ideally be based on informing research audits of teaching, and would aim to raise awareness among academic staff of the language and literacy dimensions of all academic activity, as they support learners' literacy development. An important goal would be to clarify the performance standards that are expected of students in oral and written communication.

Reid and Parker (2002) cite a fourteen-country survey of 20,000 academics in which two-thirds expressed dissatisfaction with the written language skills of their students, ample justification for including communication issues within formal institutional policies. The increasing language and cultural diversity of student populations, and indeed of faculty, induce Borland and Pearce to argue, 'a major shortcoming of the modern multicultural university has been the failure to adequately understand the implications of diversity in relation to students' language, literacy and cultural understanding' (2002: 103).

Literacy, understood as an expression of a wider analysis of communication issues in general, needs to be addressed in addition to access research and theory development for higher education. Theorising widening access needs to foreground literacy as the principal practice of higher learning, the mediator of knowledge and skill, and the identity marker of the communities of practice that constitute both institutional life and the professional destinations of graduates.

\section{References}

Absalom, D. and Golebiowski, Z. (2002) 'Tertiary literacy on the cusp', Australian Review of Applied Linguistics, 25(2), 5-18.

Australian Bureau of Statistics (1996) Aspects of Literacy: Assessed Skill Levels, Australia, Canberra: Australian Bureau of Statistics.

Barton, D. and Hamilton, M. (1998) Local Literacies: Reading and Writing in one Community, London: Routledge.

Barton, D., Hamilton, M. and Ivanic, R. (2000) Situated Literacies: Reading and Writing in Context, London: Routledge.

Baynham, M. (1995) Literacy Practices: Investigating Literacy in Social Contexts, London: Routledge.

Baynham, M. (2003) 'Adult literacy', in J. Bourne and E. Reid (eds) Language Education, World Yearbook of Education, London: Kogan Page.

Bock, Z. and Gough, D. (2002) 'Social literacies and students in tertiary settings: lessons from South Africa', Australian Review of Applied Linguistics, 25(2), 49-58.

Borland, H. and Pearce, A. (2002) 'Identifying key dimensions of language and cultural disadvantage at university', Australian Review of Applied Linguistics, 25(2), 101-28.

Collins, J. (1995) 'Literacy and literacies', Annual Review of Anthropology, 24, 75-93.

Collins, J. (1999) 'The Ebonics controversy in context: literacies, subjectivities, and language ideologies in the United States', in J. Blommaert (ed.) Language Ideological Debates, The Hague: Mouton de Gruyter.

Cope, B. and Kalantzis, M. (2000) Multiliteracies: Literacy Learning and the Design of Social Futures, London: Routledge. 
Falk, I. (2001) 'Sleight of hand: job myths, literacy and social capital', in J. Lo Bianco and R. Wickert (eds) Australian Policy Activism in Language and Literacy, Melbourne: Language Australia Publications.

Freebody, P. and Luke, A. (1990) 'Literacy programs: debates and demands in cultural context', Prospect, 5, 7-16.

Graff, H. (2001) 'Literacy's myths and legacies: from lessons from the history of literacy, to the question of critical literacy', in P. Freebody, S. Muspratt and B. Dyer (eds) Difference, Silence, and Textual Practice. Studies in Critical Literacy, Cresskill, NJ: Hampton Press.

Hagston, J. (2002) Exploring the International Adult Literacy Survey Data: Implications for Australian Research and Policy, Melbourne: ARIS and Language Australia Publications.

Hamilton, M. (2001) 'Privileged literacies: policy, institutional process and the life of the IALS', Language and Education, 15(2-3), 178-96.

Heath, S.B. (1983) Ways with Words, Cambridge: Cambridge University Press. Hornberger, N. (ed.) (2002) The Continua of Biliteracy: a Framework for Educational Policy, Research and Practice in Multiple Settings, Bristol: Multilingual Matters.

Janks, H. (2000) 'Domination, access, diversity and design: a synthesis for critical literacy education', Educational Review, 52(2), 175-86.

Kalman, J. (1999) Writing on the Plaza: Mediated Literacy Practices among Scribes and Clients in Mexico City, Cresskill, NJ: Hampton Press.

Kirkpatrick, A. and Mulligan, D. (2002) 'Cultures of learning: critical reading in the social and applied sciences', Australian Review of Applied Linguistics, 25(2), 73-100.

Lo Bianco, J. and Freebody, P. (2001) Australian Literacies: Informing National Policy on Literacy Education, Melbourne: Language Australia Publications.

OECD (1996) Lifelong Learning For All, Paris, OECD.

OECD (1997) Literacy Skill for the Knowledge Society (Further Results of the International Adult Literacy Survey), Paris: OECD.

Olson, D.R. and Torrance, N. (2001) 'Conceptualizing literacy as a personal skill and as a social practice', in D.R. Olson and N. Torrance (eds) The Making of Literate Societies, Malden, MA, Blackwell.

Prinsloo, M. and Breier, M. (1996) The Social Uses of Literacy, Amsterdam: Benjamins. Reid, I. and Parker, L. (2002) 'Framing institutional policies on literacies', Australian Review of Applied Linguistics, 25(2), 19-28.

Street, B. (1995) Social Literacies, London: Longman.

Street, B. (ed.) (2001) Literacy and Development: Ethnographic Perspectives, London: Routledge.

Street, B. (2003) 'What's "new" in New Literacy Studies? Critical approaches to literacy in theory and practice', Current Issues in Comparative Education, 5(2), 1-19.

Wickert, R. (2001) 'Politics, activism and processes of policy production: adult literacy in Australia', in J. Lo Bianco and R. Wickert (eds) Australian Policy Activism in Language and Literacy, Melbourne: Language Australia Publications.

Wolanin, T. (2003) HEA: Reauthorizing the Higher Education Act, Issues and Options, Washington DC: The Institute for Higher Education Policy. 